\title{
Más acerca de la Memoria Dei
}

\author{
EI apriorismo del conocimiento en LUIS VIVES
}

Como es sabido, el adagio imperante en la filosofía tradicional, en relación con la teoria del conocimiento, era el omnis cognitio incipit a sensu, que parecía darse la mano con el otro de la tabula rasa in qua nihil est scriptum, con la consiguiente abstracción, que no era un añadir un apriori a la experiencia externa, como más tarde se le ocurrirá al de Königsberg, sino un desvelar, desmaterializando de alguna manera ${ }^{1}$, el contenido experimental.

Platón, aun partiendo de un fundamento auténtico, es decir, de la universalidad del conocimiento, para la que no encontraba una justificación en la singularidad y contingencia de las realidades existentes en este mundo, recurre a un apriorismo demasiado concreto, apoyado en una preexistencia mitica del alma que habria contemplado a las realidades del lugar celeste antes de su caida en este mundo de la apariencia.

Andando el tiempo a Agustín no se le escapa la razón que movió a Platón a plantear su apriorismo idealista, asi como, no extremando la postura, vio también la necesidad de insistir en el apriorismo. No se tratará aqui de ideas dormidas sino de elementos con contenido ideal o concurrentes a la idealización del conocimiento de contenido sensible. Hoy, la interpretación aprioristica, tan rica en consecuencias para una mejor comprensión del misterio de la religación del hombre con lo "divino" en su dimensión vertical, es ya historia entre los escritores agustinos de la actualidad".

El hecho de que un aristotelismo, mejor o peor interpretado, y necesario, por otra parte, en los ambientes intelectuales de la época medieval, dejase a un lado el pensamiento agustiniano, no fue

1. Hasta cinco interpretaciones distintas para explicar la abstracción nos ofrecen los partidarios de la misma. Cfr. Mufoz, S., S.J., Psychologia Philosophica. Santander 1961, 203-209.

2. Merecen destacarse las colaboraciones en distintas revistas de LOPE Crie eruelo, José Morán, Moist́s Campelo, Victorino Capánaga entre otros. 
suficiente para que el mismo sto. Tomás, con todo su aristotelismo, no fuese siguiendo las huellas agustinianas en puntos aun tan tenidos por genuinamente aristotélicos como el de la "tabula rasa".

$Y$ es ya historia también la continuación, dentro de la escuela histórica agustiniana, del apriorismo agustiniano en el conocimiento, que hoy tiene ya un nombre propio: la MEMORIA DEI en el hombre :

Pues bien, no fue sólo de puertas adentro donde se cultivó con interés esta teoría. Traemos hoy a colación al conocido filósofo del renacimiento el español Luis VIVES, y en concreto su obra De anima et vita. Es el cap. XI donde trata de la vida racional. Mediante la vida racional, que supone la vida sensitiva, y apoyándose en ella, el hombre es capaz de salir de la cárcel corporal en que se encuentra su mente como entenebrecida ${ }^{5}$ para elevarse a lo inmaterial. $\mathrm{Y}$ es aquí donde encontramos la primera alusión al apriorismo al señalar objetos que "escapan a la capacidad receptiva de los sentidos", al objeto formal de los mismos, dirian los escolásticos. Mientras que la fantasia - punto confluyente de la actividad sensitivatira del alma hacia abajo, hacia las cosas materiales, la mente corrige los excesos materiales de la fantasia ofreciendo al hombre el mundo de lo espiritual ignorado por el bruto. Es este mundo el mundo de la verdad, del juicio, de la razón, de la lógica, de todo aquello que los sentidos no pueden apreciar. En una palabra, nos encontramos aqui lo que fue para Agustín el fundamento de su apriorismo intelectual: no es captado por los sentidos lo que no es del orden sensible:

“...unde pugna et contentio, inter mentem, ac phantasiam, dum

3. CaSado, F., El apriorismo del conocimiento en Sto. Tomás de Aquino, Estudio Agustrniano 1977, 493-509.- Sodalitas Thomistica, de Roma, lleva publicados ya diez Quaderni muy tentadores a este propósito.

4. Casado, F., la teoria de la Memoria DeI en la tradición escolástica agustiniana (Extracto de la tesis doctoral, Salamanca 1967).

5. "Has sensuum, sive exteriorum, sive interiorum, facultates, supremae sunt in brutis, in homine vero menti deserviunt, quae innixa cognitione imaginationis, et phantasiae, altius in se erigit, nempe ad intelligentiam rerum spiritualium: et assequitur, se, clausam obscuro carcere, obseptamque tenebris, eoque a rerum plurimarum intellectu arceri, nec posse planius intueri, ac cognoscere quae vellet, sive essentiam rerum materia contectarum, sive qualitatem ingeniunque immaterialium, nec posse per hanc corporis caliginem acumine ac celeritate sua uti" (VIVES, L., (De anima, lib. I, c. XI. Opera omnia III, 329), 
haec deorsum trahit animum ad corporea, mens ad superna, et res praestantissimas, erigit; et fertur mens ad ea quae neque sensu ullo, nec phantasia comprehenduntur, errantemque, et divagantem longissime per devia phantasiam cohibet, atque in viam reducit" ".

Vamos a poner en claro el pensamiento de vives en este punto. En el cap. XII nos habla del principio vital que se encuentra en el hombre y en los animales, que no es la materia, y que es diverso en el uno y en los otros ". Sólo el espíritu del hombre es capaz de remontarse sobre los espacios celestes y llegar al mismo Dios, ya que tiene un origen "divino" . En el hombre se encuentran los mismos sentidos que en los animales, pero sobresale en el hombre la razón, cuyo objeto difiere del objeto de los sentidos precisamente a causa del origen de cada uno de estos objetos. Mientras la fantasia tiene un contenido sensible, recibido de los sentidos externos, la razón se desliza con raudo vuelo sobre las imágenes, y cuando algo sensible es captado por la razón, lo hace de tal manera que nada de lo sensible se le pega. Las imágenes que emplea en el texto siguiente están insinuando el origen distinto de los conocimientos sensible e inteligible:

"Phantasia nullam sibi potest figurare imaginem nisi ex his quae prius usurpavit sensibus, sive aliqua talis sit in natura rerum, sive $a b$ ipsa conficta ex una aliqua, aut diversis; ratio autem tanta rapiditate volitat per eas imagines, ut vel nullam omnium in se concipiat, vel adeo leviter, ut fere nulla esse videatur, nihil enim sumit de inhaerentibus singularibus, ideoque aspicit procul quidem, abiungit se tamen a visis quantum potest efficere..." 9.

Vamos a ver ya en casos concretos la afirmación del innatismo; son los casos de la "verdad" y del "bien". En primer lugar tenemos que el "bien" de los animales es objeto de sus sentidos y se encuentra como a la mano en los cuerpos, bastándose la estimativa para captarlo; en cambio el "bien" del hombre está en la mente y oculto, como en tinieblas, siendo necesario sacar a luz las nociones de "verdad" y de "bien" ". Pero ¿cómo se verifica esto? Es de notar aqui que Vives habla hasta de un cierto innatismo en los mismos animales; en efecto, nos dice que en el animal se encuentran ciertas

6. Ibidem.

7. "Hisce vitae ac vigoris actionibus liquido patefieri aliquid in his viventibus inesse, quod dessit torpentibus, scilicet, quod vitam illis praestet, non item his alteris: id vero fieri non potest ut sit ea moles quae silva, seu materies, dicitur" (bidem, c. XII, 330).

8. "Homo vero supra coelos etiam ascendit ad Deum ipsum; divina est ergo illius origo" (Ibidem, 334).

9. Ibidem, lib. II, c. IV, 354. 
"inclinaciones" y unas como "reglas" de actuación recibidas de Dios para la consecución de su bien. Evidentemente tenemos aquí la afirmación de un innatismo de conocimiento práctico que regula toda la actuación del animal, ya que éste en su actuación no actúa mecánicamente sino en base a un conocimiento. Ahora bien, en el hombre tenemos la prosecución de algo que no se da en los cuerpos: es la "verdad" la meta de la contemplación, y la meta de la verdad es el "bien" en lo que ha de hacerse. Pero, ia través de cuántas dificultades ha de moverse el hombre para alcanzar el bien que ha de conseguir!

Resulta que el hombre, cuya mente está ensombrecida por las tinieblas de sus pecados causadas por sus desviaciones, está tambièn sometido a ignorancia de la que nacen errores de razonamiento. Pero, entonces, ¿está el hombre en condición peor que los animales a los que se les han dado esas "inclinaciones" y algo asi como unas reglas para el bién? Más bien se ha de pensar lo contrario. Aun a pesar de todo ese entenebrecimiento mental, de la depravación de los cánones de rectitud de los que el hombre también ha participado, siguen existiendo sus "reliquias", las reliquias de lo que un dia se nos dio con tanta gratuidad ${ }^{11}$. Evidentemente todo esto está haciendo referencia a aquella ley natural escrita en el corazón del hombre y medio borrada por su mal comportamiento. Estas reliquias no son otra cosa, según Vives, sino lo que ha sido denominado por los teólogos: sindéresis o conservación; por Jerónimo, conciencia; por Basilio, "naturale iludicatorium"; por el Damasceno, luz de nuestra mente; y nos recuerda a los estoicos con sus anticipaciones y todas aquellas informaciones naturales, recibidas no de los maestros sino de Ia misma naturaleza ${ }^{12}$. Vives nos ofrece un ejemplo claro de este apriorismo intelectual en el orden ético. Esa

10. "Ratio data est homini ad inquirendum bonum ut id voluntas amplectatur; bonum bruti apertum est, nempe in corpore, nostrum in mente ocultum, ideoque nobis opus fuit vestigatione veri in tenebris, illi tenebras non habent, illorumque extimativa ad bonum tantum et malum fertur, nostra etiam ad verum et falsum" (Ibidem, 355).

11. "Nec est tamen dubitandum, quin ut muta animalia pronitates, et quasi regulas ad bonum suum quasdam a Deo acceperint, ita et homo, ad bonum suum, et propter bonum ad verum, non enim meliore conditione existimandum est fuisse procreatum a tanto artifice id quod deterius est, quam id quo nihil est sub coelo praestantius; menti nostrae magnas et densissimas nebulas scelus offudit, itaque depravati sunt recti illi canones; ex ignorantia multi errores nascuntur, quum ex illis universalibus ad species, et rerum singula, iudicium deducimus; sed restant nihilhominus in nobis reliquiae illius tanti boni, quae satis testantur quantum id fuerit quod amisimus" (Ibidem, 356).

12. "Haec a vulgo theologorum synteresis nominatur, quasi conservatio, Hieronymo est conscientia, Basilio naturale judicatorium, Damascenus lucem men- 
luz die la mente es la fuente de la rectitud para juzgar acerca de lo bueno y de lo verdadero; de ahi también irá formándose la ciencia moral y la conciencia ${ }^{13}$. Nos recuerda también el caso del Menón en Platón, en el que se concluye a que la mente viene a este mundo con una buena carga ideológica ${ }^{14}$. Pero Vives no admite una erudición innata en sentido platónico, sino como "inclinaciones" a la verdad, "semillas", si así se las quiere llamar, de futuros conocimientos éticos, artísticos, científicos ${ }^{15}$. La idoneidad para los conocimientos se deberá no sólo a la capacidad intelectual como potencia sino principalmente a esta "semillas" ${ }^{16}$. En cambio cuando se trate de algo no natural, como seria, por ejemplo, el aprendizaje de una lengua, la cual depende de la invención arbitraria de los hombres, si uno quiere llegar a conocerla, tendrá que aprenderla de un maestro a través de su sentidos ${ }^{17}$. Precisamente, si hay una posibilidad de error en el hombre es porque éste tiene que hacer sus ideas, a base de los juicios que haga y con la dificultad de prejuicios debidos a desviaciones anteriores ${ }^{14}$.

tis nostrae vocat; phylosophi quiddam tale sunt procul intuiti, qui anticipationes tradunt, et naturales informationes, quas non didicimus a magistris, vel usu, sed hausimus, et accepimus a natura, tametsi alii aliis pro magnitudine ingenii plures certioresque sunt has regulas sortiti, tum excoluntur, elimanturque usu, experimentis, disciplina, meditatione" (Ibidem, 356).

13. "Haec mentis nostrae sive lux, sive censura, qua recte, qua oblique semper ad bonum et verum divergit, et fertur prona, unde existit approbatio virtutum, et improbatio vitiorum, atque hinc leges et praecepta morum, et intus in unoquoque conscientia, quae delicta ipsa sua arguat, reprehendant, damnet, nisi penitus sensu humano careat, et degeneret in brutum" (Ibidem, 356).

14. Ex his quae diximus, difficultas explanatur, quam Plato attingit in Menone, nam is ut colligeret conditas esse humanas mentes, non rudes, sed magnis scientiis artibusque instructas..." (Ibidem, 356-357).

15. "Verum non habet mens nostra ante corpus eruditionem, sed cum conderetur, eccepit propensioues ad vera potius quam ad falsa, et ex propensione, ex congruentia, canones, sive formulas, quas si disciplinarum omnium semina libeat nuncupare nihil equidem repugno; nam quaemadmodum in ipsa terra semina sunt a Deo indita stirpium omnium, quos ipsa ultro quidem proferat, solertia tamen diligentiaque hominum excolantur, reddunturque ad usum aptiora, sic in mente uniuscuiusque semina sunt initia, origenes artium, prudentiae, scientiarum omnium" (Ibidem, 357).

16. "Quo fit ut ad omnia nascamur idonei, nec ulla est ars, aut disciplina, cuius non specimen aliquod mens nostra possit edere, rude quidem et malignum, sed aliquid tamen; perficitur autem id, cui doctrina et exercitatio accessit, ut in stirpibus ii sunt meliores aliis, quibus agricolae addita est manus ac industria" (Ibidem).

17. "Et loquor de cognitione rerum natura constantium, nam ea, quae sunt prorsus hominum excogitata ingeniis, sine praeceptore et doctrina non possunt percipi, ut lingua aliqua, Latina puta, aut Graeca, aut Hispana" (Ibidem).

18. "Homo, qui suas conjecturas sectatur, aberrat per eas semitas, quas ipse sibi fecit, regia via relicta; et bruta eiusdem speciei eodem modo agunt, nempe eandem sequentes naturae institutionem, et monita, homo, quia varie iudicat, diversissime agit, adque adversissime" (Ibidem). 
En el cap. VIII, titulado $D e$ discendi ratione, vuelve a expresar el pensamiento que acabamos de exponer. Hay, nos dice, una doble disciplina en el aprendizaje; una recibiendo de afuera; otra "sacando" (educere) de dentro. En este caso lo que se aprende sale a la luz y procede de lo que está dentro como la "semilla" está en la tierra. El maestro ayudará a dar a luz; como el sol ayuda a que las semillas germinen lo que ellas ya contienen. El texto siguiente no tiene desperdicio a este respecto:

"Disciplina est duplex, altera est appositio qualitatis in animo, ut cum lingua nova traditur, quod fit in hominum inventis; altera est eductio ingenii de potestate in actum, sicut in scientiis, artibusque, quarum est materia rei naturalis, illarum enim omnium, sicuti antea diximus, semina sunt naturaliter menti nostrae indita, velut stirpium ipsi terrae, ut nihil videatur aliud docens agere, quam quod sol cum vi sua profert ex seminibus germina, proditura alioqui per se, sed non tam feliciter, nec tam cito: docent bruta sobolem suam ut citius faciant quod per se nihilhominus facerent, ut avis pullum suum volare, felis venari mures, ut quam citissime videant eos sui similes, hoc est, in sua specie perfectos, nos vero docemus illa ut quod vel numquam facerent, vel aliter, faciant uti nos volumus, neque aliud est nostra in eis doctrina, quam assuefactio ad nihil fere aliud quam ad corporale exercendum aliquid, ut loqui, currere, aut modo aliquo corpus, seu corporia partem aliquam movere; brutum ad sua edoctum est magisterio naturae, nos indigemus, et nostra exercitatione, et admonitione aliena, ut proferamus quod est inditum" 19 .

Terminamos con estas otras palabras del mismo autor:

"Quam bene egit Deus cum homine, ut quod necessarium esset tam in obvio proposuerit! nihil utilius quam multa discere, nihil facilius quam multa audire; ipsum quoque ingenium in quibusàam hominum, natura sua dextrum, et felix, vel tenuissima ope extrinsecus adiutum, mirifice sese extendit et dilatat, suique ipsius magister est atque insititutor, nec perinde a sensibus doceri, nec, etiam interdum ab homine magistro potest, ut docetur a semetipso unde sunt illi automazeis ${ }^{20}$.

Fidel Casado

19. Ibidem, c. VIII, 372.

20. Ibidem, 373-374. 